\title{
Heritability and Components of Resistance to Cercospora zeae-maydis Derived from Maize Inbred VO613Y
}

\author{
Stuart G. Gordon, Patrick E. Lipps, and Richard C. Pratt
}

First and second authors: Department of Plant Pathology, and third author: Department of Horticulture and Crop Science, The Ohio State University, Ohio Agricultural Research and Development Center, Wooster, OH 44691.

Accepted for publication 22 December 2005.

\begin{abstract}
Gordon, S. G., Lipps, P. E., and Pratt, R. C. 2006. Heritability and components of resistance to Cercospora zeae-maydis derived from maize inbred VO613Y. Phytopathology 96:593-598.

Gray leaf spot (GLS), caused by the fungus Cercospora zeae-maydis, is one of the most important foliar diseases of maize. This study was undertaken to estimate heritability of C. zeae-maydis resistance and examine the relationship between previously identified resistance loci and certain components of resistance including incubation period, lesion number, and maximum lesion length. Partially inbred progenies arising from hybridization between maize inbred lines VO613Y (high level of partial resistance) and Pa405 (susceptible) were examined in Ohio and South Africa.

Heritability estimates of resistance were calculated based on severity and incubation period values. The range of heritability estimates based on severity was broad, with values ranging from approximately 0.46 to 0.81 $($ mean $=0.59)$. Estimates of mean heritability for incubation period were lowest (0.18), indicating that this component would likely be unsuitable for selection of germ plasm intended for deployment in diverse regions. Length of GLS lesions was significantly affected by host genotype, with resistant genotypes having shorter lesions from one site in Ohio during two seasons. Genotype also had a significant effect on incubation period and lesion number; the lower values for these components also were associated with resistant genotypes. The combined action of these resistance components resulted in lower overall disease severity.
\end{abstract}

Gray leaf spot (GLS), caused by the fungal pathogen Cercospora zeae-maydis Tehon \& Daniels, is one of the most important foliar diseases of maize (Zea mays L.) worldwide (46). In 1995, GLS reached epidemic proportions in many maize-producing regions of the United States (34). An estimated $10 \%$ of the Ohio maize crop was lost in 1995 due to GLS $(25,43)$. Depending on the host and environmental conditions, GLS can cause yield reductions in excess of $50 \%(22,25,46)$.

Warm, humid conditions $\left(22\right.$ to $30^{\circ} \mathrm{C}$ with periods of prolonged fog or dew) favor the development of GLS. Fields planted along rivers or other low-lying areas are most likely to experience severe GLS epidemics $(4,24,37)$. Widespread adoption of conservation tillage practices to reduce soil erosion, with the associated higher levels of residue remaining on the soil surface, and continuous planting of predominantly susceptible maize cultivars helped spread the range of $C$. zeae-maydis and increased the incidence of GLS in the U.S. Corn Belt $(11,22,46)$. In tropical environments where little conservation tillage is practiced, the use of susceptible genotypes in environments highly conducive to the disease has resulted in rapid spread of GLS where it was previously unknown $(2,5,31,33)$. The rapidity with which GLS became endemic was probably exacerbated by production of multiple crops of maize in the same area during the same year, combined with the widespread use of stover (dry stalks) as mulch for other

Corresponding author: R. C. Pratt; E-mail address: pratt.3@osu.edu

The Ohio State University-Ohio Agricultural Research and Development Center Journal Paper No. HCS05-21. Salaries and research support provided by state and federal funds appropriated to the Ohio State University, Ohio Agricultural Research and Development Center. The mention of firm names or trade products does not imply that they are endorsed or recommended by The Ohio State University over other firms or similar products not mentioned.

DOI: 10.1094/PHYTO-96-0593

(C) 2006 The American Phytopathological Society adjacent crops (e.g., bananas), in complex agroecosystems characteristic of sub-Saharan Africa (3).

Efforts to manage GLS have focused on genetic resistance. Screening efforts have revealed diverse sources of resistance $(9,27,33,45)$. Many researchers examined the genetic basis of resistance by generation means and diallel analyses $(10,12,19$, $21,44)$ and molecular mapping $(6,8,20,39)$. Resistance to $C$. zeaemaydis is quantitative (partial resistance) and additive effects are predominant, but dominance is significant as well. Complete resistance to $C$. zeae-maydis has not been identified $(17,18,20)$.

The South African maize inbred VO613Y possesses a high degree of partial resistance to C. zeae-maydis (20). In a mapping population evaluated in both the United States and South Africa, Gordon et al. (20) identified two quantitative trait loci (QTL) from VO613Y that accounted for $46 \%$ of the phenotypic variation in GLS severity. These QTL were located on the long arms of chromosomes two and four (20).

Breeding for resistance has typically relied on various disease severity assessments of individual plants or plots taken at various times during the epiphytotic or a single assessment taken near maximum GLS severity $(28,38)$. Freppon et al. (16) proposed screening for resistant lesion types in addition to severity assessments for selection of resistant breeding lines. The chlorotic lesion response can limit GLS severity. Monogenic inheritance of this resistance response has been reported (17). However, this lesion response is specific to certain genotypes (17). Smith and Kinsey (41) suggested using latent period, which they defined as the days from inoculation to lesion formation, as an effective selection criterion for Exserohilum turcicum resistance in maize. They demonstrated that latent period was negatively correlated with lesion area on a whole-plant basis. Development of partially resistant varieties would be aided by knowledge of the relative contributions of incubation period, lesion length, and number of lesions to disease severity (17).

Heritability estimates allow breeders to develop more efficient selection strategies (population structure and size, selection differ- 
ential) and to predict gain from selection (1). QTL for resistance to $C$. zeae-maydis have been identified $(6,20,23,39)$, but only a few estimates of the heritability of resistance have been calculated. Clements et al. (8) estimated the broad-sense heritability of percent leaf area affected by $C$. zeae-maydis at 0.73 . While it is useful to have an estimate of the total genetic effect on a particular trait, such as broad-sense heritability, narrow-sense heritability provides a better estimate of the breeding value (1). Parentoffspring regression is an effective means of estimating breeding value (14).

The objectives of this work were (i) to estimate the heritability of resistance to $C$. zeae-maydis infection based on disease severity and incubation period; (ii) to determine if length of incubation period, lesion number, and maximum lesion length vary significantly between related resistant and susceptible partially inbred progeny lines; and (iii) to determine if resistant progeny lines have resistant parental alleles at QTL previously associated with C. zeae-maydis resistance from VO613Y.

\section{MATERIALS AND METHODS}

Plant material. Single plants of VO613Y, a C. zeae-maydis resistant inbred line developed in the Republic of South Africa (RSA), and Pa405, a susceptible Corn Belt inbred, were crossed. The resultant $F_{1}$ plant was self-pollinated to yield $F_{2}$ seed $(18,20)$. $\mathrm{F}_{2: 3}$ progeny lines were derived from single $\mathrm{F}_{2}$ plants and $\mathrm{F}_{2: 4}$ progeny lines were derived from single ears obtained through self-pollination of one plant within each of the $144 \mathrm{~F}_{2: 3}$ lines planted at Wooster, $\mathrm{OH}$, in 1998. Controlled pollination techniques were used. All progenies shared identity through descent within pedigreed family lines. Self-pollination to advance another filial generation provided more homozygous and homogeneous material with which to confirm the phenotypic classification in the previous generation, and increased the proportion of additive variation. Forty-six $\mathrm{F}_{2: 4}$ lines that fell approximately one standard deviation from the population mean based on maximum GLS severity data collected at Wooster and Cedara, RSA, in 1998 were chosen for further phenotypic evaluation. These were the same lines that had been used for selective genotyping (26) of the resistant and susceptible classes in a previous study (20).

Phenotypic evaluations of $F_{2: 3}$ population host responses to infection by $C$. zeae-maydis. One hundred forty-four $\mathrm{F}_{2: 3}$ lines were evaluated at Wooster and Cedara, RSA, in 1998. Plots were planted at Wooster in a simple $12 \times 12$ lattice design (two replicates) in Typic Fragiudalfs (Wooster silt loam) soil. Each plot was a single row into which 25 seeds were sown. Parental check plots were incorporated into guard rows. All plots in Ohio were $5 \mathrm{~m}$ long with $0.75 \mathrm{~m}$ row spacing, and were planted and maintained according to standard agronomic practices (30) with the following exceptions: nitrogen was applied at a rate of $55 \mathrm{~kg} / \mathrm{ha}$ and chlorpyrifos insecticide (diethoxy-sulfanylidene-(3,5,6-trichloropyridin-2-yl)oxy-phosphorane) was applied in the furrow with the seed at planting. Weeds were controlled with herbicides, and hand-weeding was performed as necessary in all plots.

Plots at Cedara were $4.5 \mathrm{~m}$ long with $0.8 \mathrm{~m}$ between plots arranged in a randomized complete block with two replications. The fertilizer regime was $450 \mathrm{~kg} / \mathrm{ha}(30 \mathrm{~N}, 45 \mathrm{P}, 60 \mathrm{~K})$ followed by a top dress of $200 \mathrm{~kg} / \mathrm{ha}$ of $28 \% \mathrm{~N}$. Herbicide spray regime was EPTC (s-ethyl dipropylthiocarbamate at 4.0 liter/ha), atrazine (2-chloro-4-ethylamino-6-isopropyl amino1,3,5-triazine dimethenamide, 3.5 liter/ha) pre-plant, and metolachlor (2-chloro- $N$-(2-ethyl-6-methylphenyl)- $N$-(2-methoxy-1methylethyl) acetamide at 0.65 liter/ha) post-plant. The insecticides deltamethrin ((s)-alpha-cyano-3-phenoxybenzyl-(1R,3R)-3(2,2-dibromovinyl)-2,2-dimethyl cyclopropanecarboxylate) and monocrotophos (dimethyl phosphate of 3-hydroxy- $N$-methyl-ciscrotonamide) were applied after planting at 0.2 and 0.75 liter/ha, respectively. The soil type at Cedara is Clay Plinthusalf (kaolinitic thermic).

The 1998 Wooster plots were inoculated four times at 7-day intervals starting the last week of July. Plants were at the V9 to V15 growth stages (36). Inoculum was grown on sorghum (Sorghum bicolor L.) kernels (20). Five to ten sorghum kernels were dropped into the leaf whorl of every plant in each plot ensuring that ear leaves were directly exposed to kernels. For 2 weeks following inoculation, low volume overhead sprinkler irrigation was used to apply water each day for approximately $30 \mathrm{~min}$ at dawn and at dusk to extend the leaf wetness period if natural precipitation had not occurred during the previous $24 \mathrm{~h}$.

Natural inoculum was sufficient for disease development at the Apple Creek and Cedara sites. Inoculum for the Wooster site (in 1999) was prepared as previously described, except that inoculum was grown on oat (Avena sativa L.) kernels (16).

Phenotypic evaluations of $\mathrm{F}_{2: 4}$ population host responses. The 46 selected $F_{2: 4}$ lines were evaluated at Wooster in 1999 , at Apple Creek, OH in 2000 and 2001, at a site that had been under conservation tillage maize production for at least 10 years, and at Cedara in 2001. In the 2001 Cedara experiment, $46 \mathrm{~F}_{2: 4}$ lines representing the resistant and susceptible tails, plus 54 randomly selected lines within one standard deviation of the population mean GLS severity values, were grown. The agronomic practices and disease evaluation methodology were the same as in 1998. A randomized complete block design with two replicates was used at each location. In addition to the $\mathrm{F}_{2: 4}$ progeny lines and parents evaluated, the inbreds NC250A (resistant) (16), Va14 (resistant) (39), Pa875 (resistant) (13), B103 (susceptible) (personal observation), and B73 (susceptible) (39) were evaluated as controls at Apple Creek.

Disease severity assessments. Five plants per plot were selected for severity assessments. These were tagged with surveyors tape prior to assessments to insure that the same plants were rated each time. The end plants of each plot were not rated in order to avoid possible border effects. GLS severity was assessed by rating a single leaf per plant at mid-plant height (usually the ear leaf) using the percent leaf area affected scale developed by Smith (42). This scale assigns a severity value based on visual estimates of the percentage of leaf surface area covered by lesions, 0 to $100 \%$. Mid-plant leaves were chosen because leaves at that position and above contribute most to grain yield (36). Given the high degree of resistance of some lines, plants with no lesions on the mid-plant leaf received a score of $0 \%$, even if not completely devoid of lesions on lower leaves. GLS severity assessments were performed five times in 1998 with approximately 7 days between assessments, beginning the third week of August. The rating methodology in Cedara was the same as in Wooster, but natural inoculum was relied on.

Resistance components measurements: Incubation period. The incubation period was recorded as the number of days from the second inoculation until the first lesions were observed. The second inoculation date was chosen because at that time most lines of the population were at the R1 growth stage (36). Since there was no transgressive segregation for incubation period (i.e., no progeny lines had shorter incubation periods than Pa405), the incubation period was standardized across experiments to the number of days after Pa405 displayed GLS lesions. The incubation period in days was averaged across replications for all rows in all evaluation sites.

Lesion length. In 2000 and 2001, the two parental inbreds VO613Y and Pa405, plus B73, along with four resistant (VP50, VP90, VP98, and VP136) and four susceptible (VP91, VP116, VP120, and VP139) $\mathrm{F}_{2: 4}$ progeny lines of the VO613Y by Pa405 cross described above were evaluated for reaction to $C$. zeaemaydis in a reduced-tillage, continuous maize field near Apple Creek, OH. Beginning approximately 10 days after flowering, R2 growth stage (36), two lesions on the leaf nearest mid-plant (usu- 
ally primary ear leaf) of each of five selected plants per plot were marked with a nonphytotoxic pen. Lesion length measurements were taken on three dates at 7-day intervals beginning on the day the lesions were first marked. The same lesions were measured each time.

Lesion number. In 2001 at Apple Creek, the number of lesions per unit leaf area $\left(75 \mathrm{~cm}^{2}\right)$ was recorded using a plastic sample grid $(5 \times 15 \mathrm{~cm})$ from ear or mid-plant leaves on the same selected resistant and susceptible $\mathrm{F}_{2: 4}$ progeny lines evaluated for lesion length. Lesions were counted near the central area of the leaf, approximately $10 \mathrm{~cm}$ from the base of the leaf blade.

Sporulation. Previous studies with diverse maize inbreds (16) failed to show a significant correlation between resistance (based on severity) and sporulation within lesions. To confirm whether or not a relationship might exist in this population, in 2000 at Apple Creek, lesion sporulation was determined by excising and measuring two intact lesions from the ear leaves of five plants per plot. The lesion tissue was placed on a wire screen in a petri dish with moistened filter paper on the bottom. Petri dishes were maintained on a lab bench at room temperature for $48 \mathrm{~h}$ under continuous fluorescent light $\left(320 \mu \mathrm{E} / \mathrm{m}^{2} / \mathrm{s}\right)$. After $48 \mathrm{~h}$, the lesions were placed in 10-ml test tubes containing $2 \mathrm{ml}$ of distilled water and agitated for approximately $10 \mathrm{~s}$ with a bench-top vortexer. The resulting spore suspension was pipetted onto a hemacytometer, and the conidia were counted and recorded as the number of conidia per unit area $\left(\times 10^{4}\right) / \mathrm{mm}^{2}$ of leaf lesion.

Maturity. Plant maturity may interact with expression of resistance. To confirm whether such a relationship existed in this population, flowering dates were recorded from the $\mathrm{F}_{2: 4}$ population grown at Apple Creek in 2000. The average number of days to silk emergence was recorded as the number of days from planting to when $50 \%$ of the plants in the plot had emerged silks. To determine if resistance to $C$. zeae-maydis was associated with maturity, correlation analysis was performed using days to silk emergence and maximum severity values.

Genotypic analysis. $\mathrm{F}_{2: 4}$ lines were genotyped using simple sequence repeat (SSR) and restriction fragment length polymorphism (RFLP) molecular markers as described previously (20). A total of 97 individual markers, including 50 SSRs and 47 RFLPs, were used for analysis of variance (ANOVA) with incubation period data as the dependent variable (described below). Genome coverage ranged from 6 to 13 markers per chromosome as follows: chromosome 1: bnlg1832, bnlg1811, bnlg1614, bnlg1112, bnlg147, bnlg2238, bnlg1884, bnlg182, umc58, umc84, bnlg131, bnl5.59, bnlg149, phi095, umc72, and umc133; chromosome 2: bnlg371, bnlg1045, bnlg1520, umc255, asg20, umc36, umc137, and csu6; chromosome 3: phi073, bnlg1523, bnlg1144, bnlg2136, bnlg1449, umc102, umc32, bnl8.35, umc63, bnlg1496, bnlg1160, and phi046; chromosome 4: nc005, phi072, umc1067, umc169, bnlg15.07, umc127, umc 42, php20608, and bnlg589; chromosome 5: mmc282, phi100, npi409, umc43, umc108, phi085, php1017, and mac.BO3; chromosome 6: npi373, umc59, umc65, umc21 umc134, umc1023, phi089, phi077, bnlg1371, bnlg345, and bnlg1740; chromosome 7: bnlg1200, bnlg155, umc168, asg49, $u m c 35$, umc 245, and umc254; chromosome 8: umc124, bnlg162, agrr21, umc117, and bnlg119; chromosome 9: bnlg1525, phi065, bnlg1714, bnlg1724, umc113, umc109, asg12, umc25, bnlg127, csu54, and umc94; and chromosome 10: npi232, npi285, phi063, umc130, umc259, npi287, bnlg1839, bnlg1526, and umc 44 .

Previously, two markers, bnlg1520 from chromosome (location) bin 2.09, and $u m c 127$ from bin 4.08, were significantly $(P<$ 0.05 ) associated with lower GLS severity (20). The genotypes of the four resistant (VP50, VP90, VP98, and VP136) and four susceptible (VP91, VP116, VP120, and VP139) $\mathrm{F}_{2: 4}$ lines at these marker loci were analyzed for their effect on lesion number and lesion length.

Data analysis. Heritability was estimated by regressing progeny $\left(\mathrm{F}_{2: 4}\right)$ values for GLS severity (PLAA) and incubation period on parental $\left(\mathrm{F}_{2: 3}\right)$ values (29). For the Cedara 2001 location, severity values of $97 \mathrm{~F}_{2: 4}$ families were regressed on their $\mathrm{F}_{2: 3}$ parental values. For all other locations, and all incubation period heritability estimates, the values of $46 \mathrm{~F}_{2: 4}$ families selected from the resistant and susceptible tails of the $\mathrm{F}_{2: 4}$ population (20) were regressed on their $F_{2: 3}$ parental values. Because lesion length and lesion count data were only taken from a selected population of $\mathrm{F}_{2: 4}$ lines, these data were not used for heritability estimates.

Main effects of genotype, location, and replicate on lesion length, lesion length area under disease progress curve (AUDPC), sporulation, and lesion numbers data collected at Apple Creek in 2000 and 2001 were determined by ANOVA. Fisher's protected least significant difference (LSD) was used for mean separation.

For lesion length, analysis was conducted using the plot mean maximum lesion length measurements of 40 lesions ( 2 lesions per plant $\times 5$ plants per plot $\times 2$ reps per year $\times 2$ years) and 11 genotypes (eight progeny lines, four resistant and four susceptible plus Pa405, VO613Y, and B73). ANOVA was performed using the PROC GLM procedure of SAS (SAS Institute, Cary, NC; 40) with maximum mean lesion length values as the dependent variable and rep within location as the error term. Locations and replications were considered random effects. Single factor ANOVA marker analysis to detect QTL associated with incubation period was performed using the PROC GLM procedure of SAS with incubation period, in days, as the dependent variable and marker within genotype as the error term.

The proportion of the variance attributable to molecular markers $u m c 127$ and $b n \lg 1520$ that were significantly associated with resistance loci was calculated by dividing the marker variance by the total variance. The variance components were calculated by a restricted maximum likelihood procedure, PROC VARCOMP, method $=$ REML, using SAS.

\section{RESULTS}

Heritability of resistance. GLS severity was evaluated in an $\mathrm{F}_{2: 3}$ population at Wooster and Cedara in 1998 and in an $\mathrm{F}_{2: 4}$ population at Wooster in 1999, at Apple Creek in 2000 and 2001, and at Cedara in 2001. Heritability was estimated by parent-offspring regression across environments within Ohio and RSA and across macroenvironments. The range in heritability estimates based on GLS severity was broad and values were moderate to high, 0.46 to 0.81 , depending on the locations used in the regression analysis (Table 1). Heritability estimates of incubation period were more variable across locations, 0.07 to 0.41 , and generally lower than estimates for GLS severity (Table 1).

Components of resistance. Analysis of the lesion length data in 2000 and 2001 from Apple Creek, OH, demonstrated that the length of GLS lesions was significantly affected by the host genotype, and there was no main effect of environment or $\mathrm{G} \times \mathrm{E}$ inter-

TABLE 1. Heritability estimates of Cercospora zeae-maydis resistance based on gray leaf spot severity assessments and incubation period by parentoffspring regression $\mathrm{x}$

\begin{tabular}{llcc}
\hline $\mathrm{F}_{2: 3}$ location & $\mathrm{F}_{2: 4}$ location & Severity $^{\mathrm{y}}$ & ${\text { Incubation } \text { period }^{\mathrm{z}}}$ \\
\hline C1998* & $\mathrm{C} 2001^{*}$ & 0.46 & 0.07 \\
$\mathrm{~W} 1998^{* *}$ & $\mathrm{~W} 1999 * *$ & 0.57 & 0.29 \\
$\mathrm{~W} 1998^{* *}$ & $\mathrm{AC} 2000^{*}$ & 0.81 & 0.41 \\
$\mathrm{~W} 1998^{* *}$ & $\mathrm{AC} 2001^{*}$ & 0.54 & 0.20 \\
$\mathrm{~W} 1998^{* *}$ & OH mean & 0.73 & $\ldots$ \\
\hline
\end{tabular}

$x$ The values of offspring $\left(\mathrm{F}_{2: 4}\right)$ were regressed on parental $\left(\mathrm{F}_{2: 3}\right)$ values. The $\mathrm{F}_{2: 3}$ population was evaluated at Cedara, Republic of South Africa, (C) and Wooster, OH, (W) in 1998. The $\mathrm{F}_{2: 4}$ population was evaluated at Apple Creek (AC), Cedara, and Wooster. $*=$ natural inoculum; $* *=$ artificially inoculated.

y Percent leaf area affected by gray leaf spot.

${ }^{\mathrm{z}}$ Incubation period was calculated as days after susceptible inbred parent Pa405 displayed gray leaf spot lesions. 
action (Table 2). The susceptible inbred Pa405 had the longest lesions (average lesion length $=14.6 \mathrm{~mm}$ ). There were no lesions on leaves at mid-plant height on resistant inbred VO613Y at this location. Lesion lengths of progeny lines ranged from 4.1 to $13.9 \mathrm{~mm}$, and averaged $10.1 \mathrm{~mm}$ on the susceptible inbred B73 (Table 3).

There were significant differences among the parents and resistant and susceptible $\mathrm{F}_{2: 4}$ progeny lines for number of lesions per unit leaf area (Table 4). VO613Y had the lowest number of lesions $(0)$ and the susceptible $\mathrm{F}_{2: 4}$ progeny line, VP116, had the highest (78). The susceptible inbred Pa405 averaged 46 lesions per $75 \mathrm{~cm}^{2}$. Other progeny lines averaged 0.5 to 45 lesions per $75 \mathrm{~cm}^{2}$.

Markers bnlg1520 (chromosome bin 2.09) and umc127 (chromosome bin 4.08) were previously linked to $C$. zeae-maydis resistance loci in this population (20). The bnlg1520 locus was linked to a recessive resistance locus (20). We examined the marker genotype of the $\mathrm{F}_{2: 4}$ lines at both loci for effect on lesion length and lesion number. Three of the four resistant $\mathrm{F}_{2: 4}$ lines with the shortest lesion lengths were homozygous for the VO613Y allele at both marker loci (Table 4).

The mean length of the incubation period of the $144 \mathrm{~F}_{2: 3}$ progeny population in 1998 was 16.7 days at Cedara and 30.9 days at Wooster (LSD $=2.0$ days). The incubation period of the susceptible parent, Pa405, averaged 10 days. No GLS symptoms were visible on the resistant parent, VO613Y, on ear leaf or leaves above the ear leaf, so incubation period could not be determined.

The main effect of genotype and the $\mathrm{G} \times \mathrm{E}$ interaction for incubation period were both highly significant $(P<0.0001)$ (Table 5$)$.

TABLE 2. Mean squares and $F$ values for gray leaf spot lesion length for $\mathrm{Pa} 405$, VO613Y, and their $\mathrm{F}_{2: 4}$ progeny lines derived by analysis of variance where data were combined across two growing seasons (2000 and 2001) at Apple Creek, $\mathrm{OH}$, with natural inoculum

\begin{tabular}{lrcccc}
\hline Source & df & $\begin{array}{c}\text { Type III sum } \\
\text { of squares }\end{array}$ & Mean square & $F$ value & $P$ value \\
\hline Genotype & 11 & 955.5 & 88.8 & 4.10 & 0.003 \\
Year & 1 & 9.2 & 4.6 & 0.20 & 0.81 \\
Rep & 1 & 0.2 & 0.2 & 0.01 & 0.93 \\
Rep(year) & 2 & 51.8 & 25.9 & 1.22 & 0.32 \\
G $\times$ E $^{\text {z }}$ & 10 & 113.4 & 11.3 & 0.54 & 0.85 \\
\hline
\end{tabular}

${ }^{\mathrm{z}} \mathrm{G} \times \mathrm{E}=$ genotype by environment interaction. Each year is considered a separate environment.

TABLE 3. Mean separation based on Fisher's least significant difference (LSD) test for the effect of genotype on lesion length, including four resistant and four susceptible $\mathrm{F}_{2: 4}$ progeny lines and the parents

\begin{tabular}{lccc}
\hline & \multicolumn{2}{c}{ Marker genotype $^{\mathrm{y}}$} & $\begin{array}{c}\text { Lesion } \\
\text { Genotype }^{\mathrm{x}}\end{array}$ \\
\cline { 2 - 3 } length $(\mathrm{mm})^{\mathrm{z}}$
\end{tabular}

x Pa405 and VO613Y are susceptible and resistant, respectively, and numbered genotypes are the $\mathrm{F}_{2: 4}$ progeny lines. $\mathrm{B} 73$ is included as an additional susceptible check inbred.

${ }^{\mathrm{y}} p p=$ homozygous Pa405 alleles, $v v=$ homozygous VO613Y alleles, $p v=$ heterozygote, and nd = no data.

${ }^{\mathrm{z}}$ Means followed by the same letter are not significantly different, $\alpha=0.05$.
The four resistant progeny lines derived from VO613Y and selected for lesion length analysis delayed the onset of the epidemic in the $\mathrm{F}_{2: 3}$ and $\mathrm{F}_{2: 4}$ populations by lengthening the incubation period relative to the population mean.

Incubation period data were used as the dependent variable to detect marker loci significantly associated with resistance in the form of longer incubation periods. Out of 86 markers analyzed across the 10 maize chromosomes, one marker, umc127 in chromosome bin 4.08, was significantly associated with longer incubation period across generations and locations by ANOVA $(P<0.03)$. The marker explained $6 \%$ of the total variation in incubation period by variance component partitioning. The genotype of the progeny lines accounted for $22 \%$ of the variation. Therefore, approximately $25 \%$ of the genetic variation was explained by $u m c 127$.

The sporulation levels within lesions were variable among genotypes with values ranging from 5.5 to 32 spores per $\mathrm{mm}^{2}$ of lesion tissue (data not shown). There was no significant main effect of genotype on sporulation level $(P=0.68)$. Variability in sporulation levels within genotypes, and lack of significant differences among genotypes varying in resistance, were consistent with earlier observations (16).

The $\mathrm{F}_{2: 4}$ populations mean number of days to silk emergence at Apple Creek in 2000 was 87 . The correlation between flowering data and PLAA was not significant among the progeny lines ( $r=-0.17 ; P=0.11)$ so no adjustments were made in the analysis of data to account for maturity effects.

\section{DISCUSSION}

Previous studies $(8,17)$ demonstrated that $C$. zeae-maydis resistance was highly heritable. Based on the parent-offspring regres-

TABLE 4. Effect of genotype on the number of gray leaf spot lesions per unit leaf area and the effect of marker genotype at resistance loci umc127 (bin 4.08 ) and bnlg1520 (bin 2.09) on lesion numbers for progeny lines derived from a cross of VO613Y (resistant parent) $\times \mathrm{Pa} 405$ (susceptible parent)

\begin{tabular}{|c|c|c|c|c|}
\hline \multirow[b]{2}{*}{ Genotype } & \multicolumn{2}{|c|}{ Marker genotype ${ }^{y}$} & \multirow{2}{*}{$\begin{array}{l}\text { Lesion } \\
\text { number }\end{array}$} & \multirow{2}{*}{$\begin{array}{c}\text { Standard } \\
\text { deviation }( \pm)^{\mathrm{z}}\end{array}$} \\
\hline & umc 127 & bnlg 1520 & & \\
\hline VP116 & $p v$ & $p p$ & 78 & $53 a$ \\
\hline $\mathrm{Pa} 405$ & $p p$ & $p p$ & 46 & $16 \mathrm{ab}$ \\
\hline VP120 & $p p$ & $p v$ & 45 & $12 \mathrm{ab}$ \\
\hline VP139 & $p p$ & $p p$ & 36 & $3 \mathrm{bc}$ \\
\hline VP91 & $p v$ & $p p$ & 36 & $3 \mathrm{bc}$ \\
\hline VP50 & $p v$ & $p p$ & 10 & $2 \mathrm{bc}$ \\
\hline VP136 & $v v$ & $v v$ & 3 & $3 c$ \\
\hline VP98 & nd & $v v$ & 2 & $2 \mathrm{c}$ \\
\hline VP90 & $v v$ & $v v$ & 0.5 & $0.5 \mathrm{c}$ \\
\hline VO613Y & $v v$ & $v v$ & 0 & $0 \mathrm{c}$ \\
\hline
\end{tabular}

$\mathrm{LSD}=40.5$

${ }^{y}$ For each marker, $p p=$ homozygote with both alleles from Pa405, $v v=$ homozygote with both alleles from VO613Y, $p v=$ heterozygote, and $\mathrm{nd}=$ no data.

${ }^{\mathrm{z}}$ Individual means followed by the same letter are not significantly different, $\alpha=0.05$.

TABLE 5. Mean square and $F$ values for incubation period across generations $\left(\mathrm{F}_{2: 3}\right.$ and $\left.\mathrm{F}_{2: 4}\right)$ and locations (Wooster and Cedara, 1998; Wooster, 1999; Apple Creek, 2000 and 2001; and Cedara, 2001) derived by analysis of variance

\begin{tabular}{lrccrc}
\hline Source & df & $\begin{array}{c}\text { Type III sum } \\
\text { of squares }\end{array}$ & Mean square & $F$ value & $P$ value \\
\hline Genotype & 44 & 14,305 & 260 & 4.33 & $<0.0001$ \\
Location & 5 & 12,657 & 2,531 & 34.50 & $<0.0001$ \\
Replication & 1 & 52 & 51.5 & 1.18 & 0.33 \\
G $\times \mathrm{E}^{z}$ & 5 & 13,086 & 62.1 & 1.92 & $<0.0001$ \\
\hline
\end{tabular}

${ }^{\mathrm{z}} \mathrm{G} \times \mathrm{E}=$ genotype by environment interaction. Each location is considered a separate environment. 
sions, heritability of resistance to $C$. zeae-maydis in this population was estimated to be relatively high, but with considerable variation. Parent-offspring regression is advocated as a means of estimating heritability because of the likelihood that few assumptions are violated, such as freedom of all genetic loci affecting the trait from linkage $(15,29)$. It is also the only simple method for estimating heritability that is not biased by selection on the parents $(14,29)$.

Heritability estimates of incubation period were lower and more variable than those based on disease severity. This is likely explained by the large environmental effect on the infection process and development of GLS lesions. Because of its lower heritability, and the increased amount of time necessary to assess this trait, incubation period is probably not as useful a measure of resistance as severity estimates for breeding purposes.

Partial resistance conditioned by VO613Y extended the incubation period and resulted in fewer and shorter lesions in resistant progeny lines. Taken together, these components resulted in lower GLS severity. VO613Y and some of its progeny lines have consistently displayed very low severity values (between 0 and $2 \%$ ) across multiple environments. Therefore, it was concluded that the very high level of resistance expressed by VO613Y appears to be rate-reducing in nature, similar to that described for NC250A by Freppon et al. (17).

Due to high variability, no difference in spore production was observed between resistant and susceptible genotypes. Lack of sporulation differences may stem from the fact that sporulation occurred on dead tissue within lesions, and such tissue no longer expressed resistance. Apparently, once a necrotic lesion was established, sporulation occurred regardless of the genotype. In theory, resistant maize genotypes should develop fewer lesions capable of producing spores, and this would negatively affect the amount of secondary inoculum available for new infection. Parlevliet (32) noted that spore production is determined by the total leaf tissue area infected, indicating that the number of spores produced per lesion is less important than the number of lesions per unit of leaf area in providing secondary inoculum to drive an epidemic (7). Since lesion sporulation does not appear to be highly correlated with resistance, the most effective way to limit the number of $C$. zeae-maydis spores will be to limit the amount of infected tissue.

The number of days to silk emergence was not significantly correlated with severity values. Therefore, early or later maturing genotypes did not escape infection and resistance level was not greatly influenced by plant maturity. In order for resistant lines derived from VO613Y to be grown in the U.S. Corn Belt, their relative maturity must be suitable for Corn Belt latitudes. This genetic source of resistance to $C$. zeae-maydis could be utilized in improvement programs without significantly increasing the days to maturity.

The molecular marker umc127 was significantly associated with longer incubation period and explained $6 \%$ of the total variation for this trait. While this is a modest value, the total variation explained by the genotype was only $22 \%$. Environmental conditions have a critical effect on lesion development $(4,35)$; therefore, the genotype may have only a moderate influence on incubation period.

Gordon et al. (20) utilized both maximum disease severity and AUDPC values for QTL analysis of C. zeae-maydis resistance, and discovered the same QTL for both measures of disease severity. This suggests that a single severity assessment at or near the height of the epiphytotic is as effective at identifying resistant germ plasm as multiple severity assessments. A single assessment would require less time for evaluations and enable larger populations to be accurately assessed $(17,38)$. Therefore, if breeders seek to increase resistance to C. zeae-maydis, there is less to be gained from measuring additional components of resistance based on results presented here.
Assessments of disease severity estimate the culmination of complex interactions between the host and pathogen. It was therefore expected that one of the two QTL regions that was associated with lower severity values would likely be associated with one of the components of resistance. This study linked one of the two marker loci associated with reduced severity values, umc127 (20), to lengthened incubation period. The lower lesion number, lesser severity, and longer incubation period associated with VO613Y are useful resistance traits that should be relatively easy to introgress into susceptible maize germ plasm. Since heritability of resistance is relatively high, the markers could be used for genotypic selection in a relatively large early generation population, followed by phenotypic selection in a smaller population. We conclude that such a marker-assisted strategy should result in improved resistance of susceptible, agronomically elite germ plasm.

\section{ACKNOWLEDGMENTS}

We thank P. Paul for reviewing an earlier draft; M. Casey and A. Johnston for providing valuable technical assistance; and J. B. J. van Rensburg and J. Lake for evaluation of progenies at Cedara, RSA. S. G. Gordon received support from IPM/CRSP grant no. CR-19053425231 from USAID.

\section{LITERATURE CITED}

1. Allard, R. W. 1999. Principles of Plant Breeding. 2nd ed. John Wiley \& Sons, New York.

2. Asea, G., and Adipala, E. 2001. Epidemiology of gray leaf spot of maize under temperate and tropical environments: A review. Afr. Crop Sci. Conf. 5:339-346.

3. Asea, G., Bigirwa, G., Adipala, E., Owera, S. A. P., Pratt, R. C., and Lipps, P. E. 2002. Effect of Cercospora zeae-maydis infested maize residue on progress and spread of grey leaf spot of maize in central Uganda. Ann. Appl. Biol. 140:177-185.

4. Bhatia, A., and Munkvold, G. P. 2002. Relationships of environmental and cultural factors with severity of gray leaf spot in maize. Plant Dis. 86:1127-1133.

5. Bigirwa, G., Pratt, R. C., Adipala, E., and Lipps, P. E. 2001. Assessment of gray leaf spot and stem borer incidence and severity on maize in Uganda. Afr. Crop Sci. Conf. 4:469-474.

6. Bubeck, D. M., Goodman, M. M., Beavis, W. D., and Grant, D. 1993. Quantitative trait loci controlling resistance to gray leaf spot in maize. Crop Sci. 33:838-847.

7. Campbell, C. L., and Madden, L. V. 1990. Introduction to Plant Disease Epidemiology. John Wiley \& Sons, New York.

8. Clements, M. J., Dudley, J. W., and White, D. G. 2000. Quantitative trait loci associated with resistance to gray leaf spot of corn. Phytopathology 90:1018-1025.

9. Coates, S. T., and White, D. G. 1994. Sources of resistance to gray leaf spot in corn. Plant Dis. 78:1153-1155.

10. Coates, S. T., and White, D. G. 1998. Inheritance of resistance to gray leaf spot in crosses involving selected resistant inbred lines of corn. Phytopathology 88:872-982.

11. de Nazareno, N. R. X., Lipps, P. E., and Madden, L. V. 1992. Survival of Cercospora zeae-maydis in corn in Ohio. Plant Dis. 76:560-563.

12. Donahue, P. J., Stromberg, E. L., and Myers, S. L. 1991. Inheritance of reaction to gray leaf spot in a diallel cross of 14 maize inbreds. Crop Sci. 31:926-931.

13. Elwinger, E. F., Johnson, M. W., Hill, R. R., and Ayers, J. E. 1990. Inheritance of resistance to gray leaf spot of corn. Crop Sci. 30:350-358.

14. Foolad, M. R., and Jones, R. A. 1992. Parent-offspring regression estimates of heritability for salt tolerance during germination in tomato. Crop Sci. 32:439-442

15. Freppon, J. T. 1994. Characterization and inheritance of resistance to Cercospora zeae-maydis. Ph.D. diss. The Ohio State University, Columbus.

16. Freppon, J. T., Lipps, P. E., and Pratt, R. C. 1994. Characterization of the chlorotic lesion response by maize to Cercospora zeae-maydis. Plant Dis. 78:945-949.

17. Freppon, J. T., Pratt, R. C., and Lipps, P. E. 1996. Chlorotic lesion response of maize to Cercospora zeae-maydis and its effect on gray leaf spot disease. Phytopathology 86:733-738.

18. Gevers, H. O., and Lake, J. K. 1994. GLS1 - a major gene for resistance to gray leaf spot in maize. Suid-Afrikaanse Tydskrif vir Wetenskap 90:377-379. 
19. Gevers, H. O., Lake, J. K., and Hohls, T. 1994. Diallel cross analysis of resistance to gray leaf spot in maize. Plant Dis. 78:379-383.

20. Gordon, S. G., Bartsch, M., Matthies, I., Gevers, H. O., Lipps, P. E., and Pratt, R. C. 2004. Linkage of molecular markers to Cercospora zeaemaydis resistance in maize. Crop Sci. 44:628-636.

21. Huff, C. A., Ayers, J. E., and Hill, R. R. 1988. Inheritance of resistance in corn (Zea mays) to gray leaf spot. Phytopathology 78:790-794.

22. Latterel, F. M., and Rossi, A. E. 1983. Gray leaf spot of corn: A disease on the move. Plant Dis. 67:842-847.

23. Lehmensiek, A., Esterhuizen, A. M., van Staden, D., Nelson, S. W., and Retief, A. E. 2001. Genetic mapping of gray leaf spot (GLS) resistance genes in maize. Theor. Appl. Genet. 103:979-803.

24. Lipps, P. E. 1987. Gray leaf spot epiphytotic in Ohio corn. Plant Dis. $71: 281$.

25. Lipps, P. E., Thomison, P. R., and Pratt, R. C. 1996. Reactions of corn hybrids to gray leaf spot. Pages 163-180 in: Proc. 51st Annu. Corn and Sorghum Res. Conf. Am. Seed Trade Assoc., Inc., Washington, DC.

26. Lynch, M., and Walsh, B. 1998. Genetics and Analysis of Quantitative Traits. Sinauer Associates, Sunderland, MA.

27. Menkir, A., and Adepoju, M. A. 2005. Registration of 20 tropical midaltitude maize line sources with resistance to gray leaf spot. Crop Sci. 45:803-804.

28. Menkir, A., and Ayodele, A. 2005. Genetic analysis of resistance to gray leaf spot in midaltitude maize inbred lines. Crop Sci. 45:163-170.

29. Nyquist, W. E. 1991. Estimation of heritability and prediction of selection response in plant populations. Crit. Rev. Plant Sci. 10:235-322.

30. Ohio State University Extension. 1995. Ohio Agronomy Guide, 13th ed. Bull. 472, OSUE, Columbus, OH.

31. Okori, P., Rubaihayo, P. R., Adipala, E., and Dixelius, C. 2004. Interactive effects of host, pathogen and mineral nutrition on grey leaf spot epidemics in Uganda. Eur. J. Plant Pathol. 110:119-128.

32. Parlevliet, J. E. 1979. Components of resistance that reduce the rate of epidemic development. Annu. Rev. Phytopathol. 17:203-222.

33. Pratt, R. C., and Gordon, S. 2006. Breeding for resistance to foliar pathogens of maize. Plant Breed. Rev. 27:119-173.
34. Pratt, R. C., Lipps, P. E., and Freppon, J. T. 1997. Multidisciplinary research on host resistance of maize to gray leaf spot. Afr. Crop Sci. Proc. 3:903-911.

35. Ringer, C. E., and Grybauskas, A. P. 1995. Infection cycle components and disease progress of gray leaf spot on field corn. Plant Dis. 79:24-28.

36. Ritchie, S. W., Hanway, J. J., and Benson, G. O. 1989. How a corn plant develops. Iowa State University, Cooperative Extension Service. Special Rep. No. 48.

37. Rupe, J. C., Siegel, M. R., and Hartman, J. R. 1982. Influence of environment and plant maturity on gray leaf spot of corn caused by Cercospora zeae-maydis. Phytopathology 72:1587-1591.

38. Saghai-Maroof, M. A., Van Scoyoc, S. W., Yu, Y. G., and Stromberg, E. L. 1993. Gray leaf spot disease of maize: Rating methodology and inbred line evaluation. Plant Dis. 77:583-587.

39. Saghai-Maroof, M. A., Yue, Y. G., Xiang, Z. X., Stromberg, E. L., and Rufener, G. K. 1996. Identification of quantitative trait loci controlling resistance to gray leaf spot. Theor. Appl. Genet. 93:539-546.

40. SAS Institute. 1985. SAS User's Guide: Statistics. 5th ed. SAS Institute, Cary, NC.

41. Smith, D. R., and Kinsey, J. G. 1993. Latent period - A possible selection tool for Exserohilum turcicum resistance in corn (Zea mays L.). Maydica 38:205-208

42. Smith, K. L. 1989. Epidemiology of gray leaf spot of field corn (Zea mays L.) caused by Cercospora zeae-maydis Tehon \& Daniels. Ph.D. diss. The University of Maryland, College Park.

43. Thomison, P. R., and Lipps, P. E. 1997. Evaluation of corn hybrids for reaction to gray leaf spot. The Ohio State Univ. Plant Pathol. Series 103.

44. Thompson, D. L., Berquist, R. R., Payne, G. A., Bowman, D. T., and Goodman, M. M. 1987. Inheritance of resistance to gray leaf spot in maize. Crop Sci. 27:243-246.

45. Ward, J. M. J., Laing, M. D., and Cairns, A. L. P. 1997. Management practices to reduce gray leaf spot of maize. Crop Sci. 37:1257-1262.

46. Ward, J. M. J., Stromberg, E. L., Nowell, D. C., and Nutter, F. W. 1999. Gray leaf spot: A disease of global importance in maize production. Plant Dis. 83:884-895 